\author{
Vladimir P. Goss
}

\title{
Laura Chinellato: L'ara di Ratchis a Cividale
}

Udine: Forum, 2016, 272 pp.

A Comprehensive Biography of a Keystone Monument. Laura Chinellato's Lara di Ratchis a Cividale and European Culture

A good mosaic should have a clear-cut frame, a central panel proposing the main subject, and subsidiary ones amplifying the theme. Laura Chinellato's Lara di Ratchis a Cividale is indeed such a successful mosaic of words and ideas. Its frame is made up of a prelude and postlude by two distinguished medieval art scholars, Valentino Pace and Hjalmar Torp; its centerpiece consists of the author's extensive and enlightened formal, iconographic, epigraphic and material analysis and is further amplified by experts in related areas - Stefano Gasparri (history), Laris della Pietra (liturgy), Maria Teresa Constantini, (conservation, restoration, reconstruction of polychromy), and Alessandro Princivalle and Davide Manzato (scientific analysis and measurements). All in all, this book is a model enterprise creating a material and spiritual ID, indeed a biography, of a key work of Pre-Romanesque figurative arts. As emphasized by Valentino Pace in his Preface, the Altar of Ratchis is "among the most important monuments of the $8^{\text {th }}$ century", one in which "epigraphy, figured images, signs, material and color converge to communicate a message of faith and prestige, which this book helps us understand". But it is also a station on a way to the future, for, as stated by Hjalmar Torp in his concluding remarks, this is a work "based on twelve years of research which includes a detailed analysis of 300 years of scholarship constitutes ... a firm point of continuous research."

Mosaics are made from tesserae that must be placed together with painstaking care in order to convey sensible images and content. This has been accomplished with laudable skill, and with a well defined objective. Through a comprehensive review of previous research from such pioneers as Fontanini, Bertolli, or De Rubei, to the outstanding scholars of a less distant past - Cechelli, Fillitz, Volbach, Angiola Maria Romanini - to the problems of provenance, musealization, conservation, physical examination, and reconstruction, the author carefully builds her portrait of the Ara as a living being, a witness to something important and relevant for our own predicaments. She creates this portrait through reading and recording the facts without any preconceived theories or preferences. One might say, strangely detached, but, surprisingly, such a detached approach imbues the object and its period - locus 
et tempus - with an aura of love and warmth, including also a genuine appreciation of those who created it, studied it, and preserved it. In the Secolo ottavo, secolo inquieto, to use Professor Pace's designation of the period, the Altar of Dux, later Rex, Ratchis stands as a unique act of merging several worlds into a cultural landscape responsible, eventually, for our joint European culture.

It is especially fascinating to participate in the process of the rediscovery of the polychromy, an incredible feat that may forever change the way we look at and evaluate works of art of the past, as the traditional vehicles of carving, painting, weaving, and metalwork, are fused into one single act - the creation of image.

This year we mark the one hundred and fifteenth anniversary of Orient oder Rom?, the controversial book by Josef Strzygowski. The debates that ensued - first of all between Strzygowski and Wilpert, dividing the world of art history between "Humanists" (Classicists) and "Barbarians" - have not quite subsided even today. In Chinellato's text, those ghosts have been quite successfully contained in their bottle. The tesserae of "both (or several) worlds" have been applied to the mosaic, but they do not clash; rather, they create a balanced picture. In that, the Altar of Ratchis, as well as Chinallato's presentation thereof, seem to fit with the concept of that "metamorphosis in progress, whose principal vector was still art," invoked by Francois Pinault in his introductory words to the Catalogue of the exhibition Rome and Barbarians in the Palazzo Grassi (J.-H. Aillagon (ed.), Rome and the Barbarians, Venice 2008, p. 31). Personally, I am an adherent of an "and - and" view of the human predicament and creativity. Without stating it explicitly, Chinellato and Co. seem to think the same.

It is refreshing to read Stefano Gasparri's "history" realizing that it is an exquisite portrait of a live people, maintaining its Longobard characteristics, but not shunning things Roman either. Or Laris della Pietra's analysis of liturgical issues showing how the unification of western liturgy took into consideration those local variants which seemed to be of a particular significance to their practitioners, so that "the Roman sobriety was integrated with the dramatic genius and the sense of the concrete of Germanic peoples." This judicious and measured approach has been used also by the author in presenting her "mosaic" of earlier opinions, ranging from such observations as Picton's (namely, that interlace sculpture had existed since ca. 2700 BC), Santangelo's stressing Roman provincial art (such as in Bosnia and Pannonia: "This is an old Roman dialect antedating the Medieval, the Longobard or Slav, but also an authentic expression of the barbarian peoples of the migration period"), Tea's (old Italic art, oriental textiles), and Mor's (popular tradition, but Latin epigraphy). The majuscule letters of the Altar's inscription are gold, the background purple, all along Roman lines; the choice and material aspects of the colors indicate knowledge of Pliny. In short, we 
encounter a very wide diapason of stylistic, iconographic, liturgical, epigraphic, and technical aspects, as the basis of the synthesis which we have already called "European Culture".

To conclude, Laura Chinellato has fashioned a very successful book on a representative monument of the cultural landscape which produced it, and on the ways its imagery acted upon this selfsame landscape. I am sure it will remain an unavoidable cornerstone of any future research of "Pre-Romanesque (stone) sculpture", an area in which there is still a wide gulf of disagreement, and a lot of work to do. In particular, she has shown how a scholar in the arts could successfully relate to and profit from his colleagues in both humanities and hard sciences in a truly multi-disciplinary manner. 